behaviour. In order to challenge the stigma surrounding genital herpes, further research is required.

\section{P116 HOW COMMON IS RECTAL CHLAMYDIA TRACHOMATIS INFECTION IN WOMEN? A SYSTEMATIC REVIEW, 1997 TO 2015}

${ }^{2}$ L Nastassya*. Chandra', Kate Folkard', Claire Broad, ${ }^{1,2}$ Emma M. Harding-Esch, ${ }^{1}$ Sarah C. Woodhall, 2,3 S. Tariq Sadiq, 'John Saunders, 'Kevin Dunbar. 'Public Health England, Colindale, London, UK; ${ }^{2}$ St George's University of London, London, UK; ${ }^{3}$ St George's Healthcare NHS Trust, London, UK

\subsection{6/sextrans-2016-052718.170}

Background Chlamydia trachomatis is the most commonly diagnosed STI in the UK. While men-who-have-sex-with-men are known to be at-risk of rectal chlamydia infection (ReCT), the prevalence and risk-factors in women are incompletely-understood. This may have important implications for testing and treatment approaches since azithromycin and doxycycline are considered first-line regimens for uncomplicated urogenital infections, whereas doxycycline is the preferred treatment for ReCT.

Objectives Undertake a systematic review to: 1) calculate ReCT positivity (number ReCT positive/number tested) among women in different testing settings; 2) determine the proportion of women diagnosed with ReCT with: a) concurrent urogenital infections and; b) a history of anal-intercourse.

Methods Medline, Embase, CINAHL, PsychINFO and the Cochrane Database were searched for articles published January 1997-September 2015. Studies reporting ReCT positivity in women aged $\geq 15$ years in high-income countries were included and relevant data extracted.

Results Fifteen studies were included (14 among women attending sexual health services). Populations tested varied e.g. 4/15 studies included only women with a history of anal-intercourse. Among all studies, ReCT positivity ranged from $0.5 \%-77 \%$ (median 13\%). Among women with ReCT, 7\%-100\% had a concurrent urogenital infection; 16\%-100\% reported anal-intercourse (where data were available; Table 1)

\begin{tabular}{|c|c|c|c|c|}
\hline & \multirow{2}{*}{$\begin{array}{l}\text { Number of studies } \\
\text { where data reported }\end{array}$} & \multicolumn{2}{|l|}{ Range (\%) } & \multirow[t]{2}{*}{ Median (\% } \\
\hline & & Minimum & Maximum & \\
\hline $\begin{array}{l}\text { Percentage testing } \\
\text { positive for Rectal } \\
\text { chlamydia (positivity) }\end{array}$ & 15 & 0.5 & 77 & 13 \\
\hline $\begin{array}{l}\text { Site of infection among } \\
\text { women testing positive } \\
\text { for chlamydia: }\end{array}$ & 12 & & & \\
\hline Rectal only & & 0 & 31 & 7 \\
\hline Rectal and urogenital & & 7 & 100 & 68 \\
\hline Urogenital only & & 0 & 86 & 18 \\
\hline $\begin{array}{l}\text { Percentage reporting } \\
\text { history of anal- } \\
\text { intercourse among } \\
\text { women testing positive } \\
\text { for rectal chlamydia }\end{array}$ & 9 & 16 & 100 & 44 \\
\hline
\end{tabular}

Conclusion ReCT infections have been found in a substantial proportion of women in the populations tested. In these studies, urogenital testing alone would have missed up to $31 \%$ of chlamydia infections. Further work to establish need, criteria and feasibility for routine ReCT testing in women is needed to ensure chlamydia infections are not missed or inadequately treated.

\section{P117 ARE WOMEN PRESCRIBED LARC LESS LIKELY TO HAVE AN ABORTION?}

${ }^{1}$ Natasha Ratna*, ${ }^{1}$ Martina Furegato, ${ }^{2}$ Paul O'Brien, ${ }^{2}$ Alyson Elliman, ${ }^{1}$ Kate Guthrie. ${ }^{1}$ Public Health England, Colindale, UK; ${ }^{2}$ The Faculty of Sexual and Reproductive Health, London, UK

\subsection{6/sextrans-2016-052718.171}

Background/introduction Almost half of pregnancies in England were estimated to be unplanned or ambivalent, and a fifth resulted in abortions. Uptake of non-injectable long-acting reversible contraception (NI-LARC) methods is recommended to reduce the risk of unplanned pregnancies and abortions.

Aim(s)/objectives To determine if NI-LARC usage reduces the risk of abortion.

Methods Attendances at Sexual and Reproductive Health (SRH) services which provided more than 10 abortions during 1/1/ 2013-31/12/2014, recorded in the SRH Activity Dataset, were considered. The risk of abortion by contraceptive method (NILARC, other methods) used at least once or no method during the study period, was estimated using the Kaplan-Meier method. Cox Proportional Hazards Models were used to estimate hazard ratios for risk of abortion by contraceptive method used, adjusted for age, ethnicity, area-level deprivation and rural/urban residence.

Results 42,210 women used NI-LARC (26.2\%), 79,380 women used other contraceptive methods (49.3\%), 39,403 women had no method (24.5\%); 2,339 women had an abortion (1.5\%). The highest proportion of women who had an abortion was reached within first month of exposure: $0.08 \%$ of women using NILARC, $1.34 \%$ of those using other contraceptive methods and $2.63 \%$ of those not on contraception. The adjusted hazard ratios for risk of abortions were 17.5 (CI 13.1-23.4) times higher in women who were not on contraception and 12.6 (9.5-16.9) times higher in women using other contraceptive methods, compared to those who used NI- LARC.

Discussion/conclusion NI-LARC use is strongly associated with reduced risk of abortion in women attending SRH services because it is independent of compliance.

\section{P118 "LARCING ABOUT" WITH INTEGRATED SERVICES: OUR GENITOURINARY MEDICINE (GUM) SERVICE USERS' VIEWS ON THE PROVISION OF SHORT \& LONG ACTING REVERSIBLE CONTRACEPTION (LARC)}

Rachel Mclntosh*, Kerry Burnett, Elisha Peter, Sam Walsh, Kimberley Forbes, Donna Nicholas, Divya Gupta, Gillian Avery, Charlotte E Cohen, Nneka Nwokolo, Sara Day. Chelsea and Westminster Hospital NHS Foundation Trust, London, UK

\subsection{6/sextrans-2016-052718.172}

Background Integrated models are promoted as the ideal way for women to receive sexual health and contraception. Commissioners advocate shifting contraceptive provision away from GUM to general practice and community settings. Given our boroughs have the lowest GP LARC prescribing rates in 